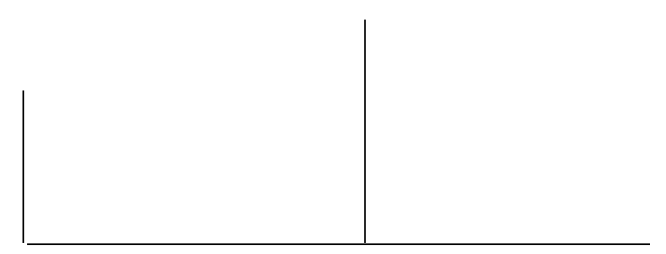

Rev. Latinoam. Psicopat. Fund., VIII, 2, 204-220

\title{
A construção do caso clínico na internação psiquiátrica: uma direção para o plano terapêutico*
}

\author{
Ademir Pacelli Ferreira
}

\begin{abstract}
A construção do caso é aqui abordada em sua pluralidade prática na internação psiquiátrica. Inicia-se com a revisão sucinta da conceituação e da metodologia do caso clínico, seguindo-se com a construção e análise do caso, em que se afirma a sua importância na direção e encaminhamento do plano terapêutico. Finalmente, chama-se a atenção para a exigência de elaboração do momento da saída da internação para o sucesso da continuidade do tratamento externo.
\end{abstract}

Palavras-chave: Caso clínico, pluralidade, construção, internação, reforma psiquiátrica 
Este texto é resultante da primeira análise de um estudo mais amplo sobre a clínica em psiquiatria. ${ }^{1} \mathrm{~A}$ análise e a discussão das controvérsias diagnósticas e psicopatológicas não serão objetos desta análise. O que queremos enfatizar aqui é mais a afirmação de uma prática interdisciplinar - onde a exigência da interlocução deve ser mantida como um princípio ético - do que a discussão das controvérsias e das disputas interprofissionais. Neste campo de experiências extremas ninguém possui a resposta, até porque esta só pode ser construída na experiência terapêutica plural. Deve-se privilegiar, portanto, um certo comunismo de idéias (Freud/Jung, 1907, p. 18F), em que a contribuição de cada um não deve ser privatizada.

A construção de um caso clínico envolve elementos do quadro psicopatológico e da organização da história clínica, mas não se define a partir daí, vai além. Trata-se do esforço de transformar em saber uma experiência cujo fim é o outro, o destinatário que poderá acolhê-lo e tornar-se testemunha desta aventura. Nesta experiência, o drama do paciente poderá desdobrar-se em novos sentidos, revelando ainda elementos contra-transferenciais que poderão ganhar visibilidade no circuito da comunicação-narrativa (cf. Hoppe, 2000). Trata-se, portanto, de uma via metodológica fundamental na elaboração da teoria em clínica.

A casuística médica sempre teve grande importância para o conhecimento da semiologia, das síndromes, do diagnóstico diferencial, da evolução e do tratamento das doenças. Confunde-se, portanto, com o próprio nascimento da clínica médica (Ferreira, 2002b). Os casos

1. O caso clínico como unidade de análise da psiquiatria e da reforma, projeto de Pós-doutorado acolhido no Laboratório de Psicopatologia Fundamental, PUC/SP, sob orientação do Prof. Dr. Manoel Tosta Berlinck. 


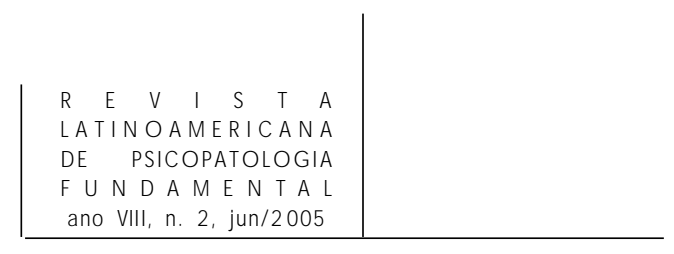

demonstram como o organismo porta, desenvolve e manifesta a doença, além das formas e recursos de que o médico dispõe para intervir nesse organismo ao visar o combate da doença. Portanto, é um método de conhecer as doenças, de comunicar e de trocar conhecimento técnico entre os médicos, além de veículo de divulgação dos conhecimentos e da perícia médica frente aos tipos de enfermidade. Mas a clínica construída na proximidade com o enfermo foi seduzida pela clínica das doenças, esquecendo-se, às vezes, do doente.

Freud, que se formou junto aos grandes clínicos do final do século XIX, desconfiou logo do furor sanandi resultante do saber da doença. Para ele, o caso clínico ganhou importância fundamental para elaborar o seu método terapêutico e a sua teoria ou metapsicologia, ultrapassando, assim, o método tradicional da medicina. A construção da psicanálise se funda na articulação estreita entre experiência e saber, entre clínica e teoria. Como afirma Fédida, citado por D’Agord (2000, p. 12), “... na psicanálise, o caso é uma teoria em gérmen, uma capacidade de transformação metapsicológica. Portanto, ele é inerente a uma atividade de construção”. Também Caon (2000) afirma que o caso psicanalítico, “... deve conter as hipóteses e constatações metapsicológicas do diagnóstico do analisante. Os fatos clínicos (...) fornecem fundamentos teóricos que explicam cientificamente os fatos clínicos relevantes” (p. 37).

\section{A construção do caso na internação psiquiátrica}

Na internação de um paciente, logo após a sua identificação no prontuário, o tópico que se segue é o motivo de sua internação. São várias as razões que podem justificar uma internação, tanto subjetivas quanto objetivas. A institucionalização da segregação do doente mental dispensava maiores justificativas, já que bastava a constatação da desrazão do louco (delírios, alucinações, comportamentos bizarros, desvarios), para levá-lo ao hospício. Ao se contrapor à internação automática, torna-se necessário estabelecer critérios para que alguém seja internado. Acontece que esta avaliação geralmente é feita de forma rápida, numa consulta psiquiátrica de emergência ou no ambulatório e nem sempre é exaustiva e discutida em equipe.

Optar pela internação significa decidir sobre a indicação de uma modalidade de assistência integral para o indivíduo, o que implica entrar num espaço de vida fora de casa e da família. Como costumamos afirmar, são 24 horas por dia, juntamente com outros internos, compartilhando os mesmos espaços. Portanto, trata-se de uma escolha justificada pela idéia de que este indivíduo ou este sujeito necessita de suportes especiais para o seu funcionamento, enquanto 
sujeito e agente social. Esta perspectiva de refletir sobre a função da internação decorre de uma crítica e de uma contraproposição ao modelo que cunhou a máxima lugar de louco é no hospício, e que predominou na psiquiatria até recentemente. Logo, para internar alguém em psiquiatria, deve-se partir de um plano de tratamento para o interno. Para tal, o estudo de caso surge como possibilidade de indicar a direção deste tratamento, onde a história clínica que justificou a internação possa se transformar em um espaço especial de acolhida, de fala e de ação que favoreçam a produção de sentidos e de singularidades.

Portanto, a construção do caso clínico na internação envolve algumas questões: o que é a internação; qual será o plano terapêutico; o que é a alta da internação e como se constroem as condições de saída e de manutenção do tratamento externo. Envolve, desta forma, um trabalho de equipe, em que o arranjo dos elementos que permitirão a sua interpretação e construção ${ }^{2}$ surgem das múltiplas implicações e de efeitos transferenciais elaborados em trocas e supervisões. Como afirma Figueiredo (2003), ${ }^{3}$ a proposta é a mesma visada pela clínica psicanalítica:

... recolher da experiência do sujeito, de seu discurso - que evidentemente tem um endereçamento, às vezes fragmentário, às vezes bem específico a determinado profissional - os elementos com os quais se fará a construção do caso, entendendo que ela é sempre parcial, visa dar direções para determinada intervenção ou ação da equipe, sendo passível de revisão na medida dos acontecimentos... (p. 8-9)

Se a construção do psicanalista é feita através da experiência da qual é testemunho individual, na internação vários agentes participam desta experiência, cada categoria inclusive com seu referencial ético, técnico e teórico. Trata-se de uma clínica suportada na pluralidade - pratique à plusieurs, segundo Miller, citado por Ciaccia (2004) ou, como propõe Figueiredo (2003, p. 8), seguindo Zenoni uma direção que aponta no sentido de "aprendizes da clínica”, onde não se impõe

2. Figueiredo define estes dois termos como se segue: “A construção é um arranjo dos elementos do discurso visando uma conduta; a interpretação é pontual visando um sentido. (...) A finalidade da construção deve ser justamente a de partilhar determinados elementos de cada caso em um trabalho conjunto, o que seria impossível na via da interpretação. Assim, a construção pode ser um método clínico de maior alcance. $\mathrm{O}$ outro termo, caso, se refere ao latim cadere que quer dizer 'cair' [Obs nossa: também no alemão temos fall - caso e queda]. Segundo Vigano (apud Figueiredo, op. cit.): "ir para fora de uma regulação simbólica; encontro direto com o real, com aquilo que não é dizível, portanto impossível de ser suportado”.

3. O texto utilizado aqui foi apresentado no VII Encontro científico da AUPPF, uma nova versão foi publicada na Revista Latinoamericana de Psicopatologia Fundamental, v. 2, 2004, p. 75-86. 


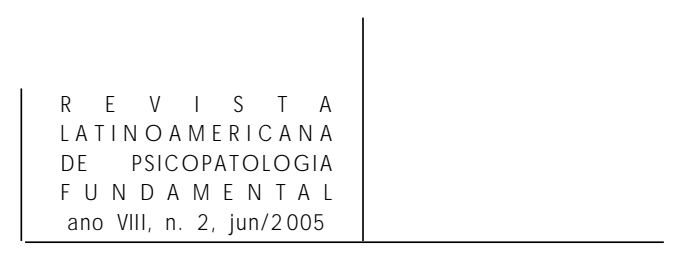

um modelo, mas se procura colher das produções do sujeito os indicadores para seu tratamento. Nesse texto, a autora segue a referência proposta por Lacan de "transferência de trabalho" que, segundo ela, opõe-se aos efeitos narcísicos imaginários, seja em relação à confusão de papéis (modelo igualitário), seja na fixação de papéis (modelo hierárquico).

O método de elaboração do caso não despreza a nomenclatura criada pela psiquiatria e pela psicopatologia geral nos dois séculos de constituição desses saberes. A descrição, nomeação e diferenciação dos sintomas não devem ser reduzidos, no entanto, ao mero exercício acadêmico para a demonstração no ensino, como uma clínica das espécies (cf. Figueiredo, 2002). Como afirma Lacan, citado por Alberti (2003), o sintoma é signo de que algo não anda bem no real. É neste sentido que se visa ir além do fenomênico no caso. Ao interrogar o ser, o sintoma se apresenta como resposta do sujeito. Não se trata, portanto, como afirma Stevens (1996, p. 24), de uma falta de ser, mas de uma forma de ser. O diagnóstico é visado, nesta perspectiva, como esforço de localizar o pathos no sujeito (cf. Figueiredo, 2003).

Para além dos sintomas captados por um olhar instrumentado pela noção de normal e patológico, há formações e manifestações do inconsciente, ou seja, desta alteridade no cerne do ser. Isto implica a tarefa de localizar o pathos e resgatar, do submetimento do sujeito, o que existe aí de positividade, ou seja, restituir a dialética deste campo de articulação eu-outro (Ferreira, 1999). É pela atividade do sujeito que se produz este movimento, onde o eu encontra mediação contra a paralisia resultante da submissão ao isso ou ao supereu. Trata-se de um processo de metabolização que a partir do pathos - por meio da acolhida, da fala, de uma experiência terapêutica - pode restituir um saber sobre o ser, ou, ainda, um ensinamento interno (cf. Berlinck, 2000, p. 21).

A clínica médica inclinou-se sobre o doente ao pé do leito. Esta posição (inclinação) - o doente estendido no leito e o médico que se aproxima para colher e identificar a enfermidade e oferecer o alívio para o seu sofrimento - ao seguir um método minucioso e sistemático de descrição e organização das observações, produziu um importante saber sobre a doença (Foucault, 1977). Mas na clínica anímica, há que se seguir ao pé da letra (Figueiredo, 2003) as produções da esfera psíquica, suas formas de organização e de manifestação. Há aí um grande trabalho artístico (cf. Freud-Jung, Correspondência, apud Nasio, 2001), edificado desde a fundação do sujeito.

No texto já citado, Figueiredo (2003), apresenta uma tríade de binômios como referência para a construção do caso. O primeiro binômio diferencia história e caso; a história seria o relato clínico, cujo conteúdo é rico em detalhes, cenas, e conteúdos, enquanto o caso seria o "produto do que se extrai das intervenções do analista na condução do tratamento e do que é decantado de seu 
relato...”. Segundo a autora, não será o montante de detalhes e a obediência a uma forma que farão a riqueza do caso, mas sim a "colocação em jogo dos significantes do sujeito e de suas produções...”.

No segundo binômio, analisa-se (idem) o lugar da supervisão na construção do caso. Trata-se de um método sustentado pelas discussões realizadas em equipe, no que caracteriza mais um trabalho de construção do que de supervisão. Já o terceiro binômio, analisa-se o lugar dos conceitos e a importância das distinções. Pontua-se aqui a necessidade de questionar os conceitos a cada passo. Como afirma a autora, “... a psicanálise não é o efeito de um saber do Outro sobre uma história e sim, o feliz encontro entre as ferramentas conceituais do analista - pulsão e objeto, por exemplo - e as contingências de uma história, produzindo um caso e, no melhor dos casos, um novo sujeito” (p. 6).

\section{Internação: oferta de acolhida ao sujeito ou refúgio para a angústia}

O caso que escolhemos analisar visa introduzir elementos para a reflexão sobre a importância da construção do caso na prática terapêutica institucional. Trata-se de uma experiência que ilustra o cotidiano do esforço de uma prática interprofissional, onde há que se superar os embates, disputas e impasses para que seja possível sustentar a discussão e afirmar o programa terapêutico. Neste caso foi possível apostar na oferta da escuta a um sujeito que parecia reduzido à identificação ao discurso médico ou à doença. Apesar dos impasses iniciais, nosso foco não será os problemas institucionais, mas sim as exigências mesmas da clínica.

Estava presente aí um real que instigava, um desespero que só encontrava expressão na súplica ao médico, súplica essa de um alívio total. Isto é, um desejo nirvânico de ver suprimido em si as marcas próprias da experiência humana, ou seja, a incompletude, os conflitos, a paixão e o desamparo (cf. Pereira, 1999). Tudo isto colocava-o em total submetimento ao discurso médico. Ser si mesmo e encarregar-se de si, tão acentuado na contemporaneidade, representa uma grande carga, como demonstra Ehremberg (cf. Oliveira, 2004) em seu La fatigue d'être soi.

A possibilidade de superação dos atritos frente às diferenças e dos impasses surgidos no cotidiano do trabalho institucional, que envolvem vários atores, como é o caso da internação, ${ }^{4}$ é fundamental para a continuidade e a sustentação de um

4. Porteiro, segurança, enfermeiros, estudantes de várias disciplinas, médicos residentes, psicólogos residentes e estagiários de graduação, terapeutas ocupacionais, assistentes sociais e especializandos, professores das respectivas disciplinas e outros. 


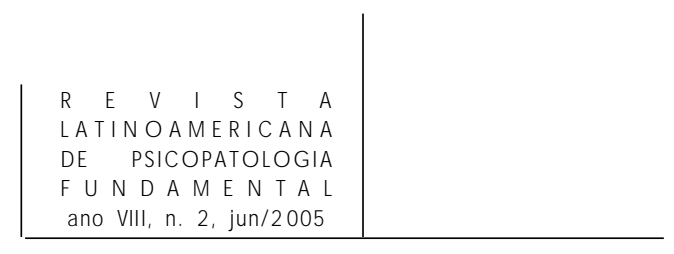

plano terapêutico, pois sem a discussão dos atos de cada um, torna-se impossível avançar no projeto comum. Cria-se aí um campo aberto à atuação, em que a disputa narcisista campeia. Felizmente, neste caso, a superação dos impasses interprofissionais permitiu a abertura e a ampliação da interlocução.

Apesar das dificuldades e da resistência da maioria dos componentes do staff - em participar da reunião de enfermaria, nesta instituição - o coordenador da Unidade tem sustentado a sua existência, contando com a participação de parte da equipe: professor e coordenador de psiquiatria, professor-supervisor de psicologia, terapeuta ocupacional, assistente social, enfermeiros, residentes, estagiários e especializandos das várias áreas, responsáveis pelo atendimento aos internos. Observa-se na instituição que os lugares e as funções ocupadas por cada um não são bem estabelecidos. Somente o médico parece ocupar um lugar mais definido, ou seja, aprioristicamente é o responsável pela internação, tratamento e alta do paciente. Mas sabemos o quanto é ilusório este lugar assinalado pelo discurso do saber. A manutenção da discussão de equipe só é possível se os lugares, as funções, os atos e as propostas de intervenção puderem ser avaliados, questionados e discutidos.

As clínicas especializadas em medicina surgiram da necessidade de se oferecer áreas de prática para a graduação e a formação das especialidades médicas. Com a demanda de formação de outros profissionais, essas clínicas deixaram de ter unicamente o domínio médico. Entretanto, ainda se mantém a hegemonia do discurso médico, o que restringe a possibilidade de maior circulação dos posicionamentos dos outros profissionais. Isto é mais acentuado no espaço da internação, seja no hospital geral ou na psiquiatria, o que dificulta a participação de todos nas discussões referentes ao diagnóstico, terapêutica e alta (veja também, Rinaldi, 2002). Mesmo em unidades universitárias (Unidades Docentes Assistenciais) responsáveis pela formação dos profissionais de saúde, só são considerados staff os professores médicos.

No caso aqui abordado, surgiu um novo elemento de surpresa: tratava-se da defesa do ato médico como sendo uma unidade de decisão e ação inquestionável por parte dos profissionais não médicos. Surgiu a indicação da eletroconvulsoterapia (ECT) para o paciente, com a justificativa de que já havia sido feito tudo e que não teria surtido efeito, portanto, por ser um paciente depressivo, a ECT era o próximo passo. Tanto o paciente quanto a família cobravam por este recurso como se fosse a salvação - o que eu costumo chamar da última solução ou de poção derradeira. No melancólico surge como algo extremo - o chamado da alteridade radical ou da morte. Isto é, se é o último, não restará mais nada a fazer.

Em nossa observação, o paciente apresentava-se muito mais angustiado do que depressivo e havia o registro recente da última internação, em que a ECT foi utilizada e não obteve o efeito esperado. Mas ao tentar contra-argumentar, 
encontramos o muro da bandeira do Ato Médico. ${ }^{5}$ Não há discussão, trata-se de um ato médico, esta foi a frase que surgiu como barreira à interlocução. Surpreendidos, confrontamos o sentido daquela reunião de equipe e estabeleceuse o impasse. Felizmente, o apelo ao trabalho em equipe prevaleceu à medida que o coordenador propôs um tempo para o tratamento e a suspensão temporária da aplicação da ECT. Com isto, oficializou-se uma dupla composta pelo residente médico, sempre muito dedicado, e pela residente psicóloga para dar direção ao programa terapêutico, o que tornou possível sustentar a oferta da residente de psicologia, que vinha conseguindo aproximar-se do interno. Em nossa experiência, aberturas como estas é que permitem o trabalho institucional ao longo dos anos.

Portanto, esta experiência vem confirmar a importância do diálogo e do intercâmbio no trabalho institucional, demonstrando que a bandeira corporativista traz efeitos corrosivos ao trabalho terapêutico, que é sempre bastante árduo e que exige humildade por parte de todos, pois é a possibilidade de troca e de convivência com as diferenças o que enriquece a todos e que resulta em benefício para os pacientes.

Ao apresentar o caso, a residente de psicologia - que foi sua psicoterapeuta de referência - deu-lhe como título "Apostando num sujeito esquecido" (Erlich, 2003). Neste caso, falamos de terapeuta de referência no sentido daquele especializando ou profissional que consegue se aproximar do paciente e sustentar uma oferta terapêutica, já que, como afirmamos anteriormente, todos os estagiários e residentes são orientados no sentido de procurar acompanhar todos os internos da enfermaria. Além disto, também os profissionais de enfermagem cuidam de todos, além do assistente social, que é designado para acompanhar cada caso. A internação se caracteriza pela oferta de uma assistência integral, mas o investimento do sujeito (interno) privilegia certas direções, direcionamentos estes que devem ser investidos.

O título acima referido focaliza a identificação maciça do paciente com o chamado discurso médico ou discurso da doença, no sentido de uma entidade endorgânica sem sentido subjetivo. Esta redução do sujeito passa por sua capturação por este discurso total, isto é, um discurso sem falhas, é a depressão. Diante da angústia, do esvaziamento de sentido e da impossibilidade do dizer, agarra-se à doença e ao remédio. Mas, como afirma Figueiredo (2003),

... na maioria das vezes os sujeitos se apresentam tutelados, desresponsabilizados, mas nem por isso sentindo-se menos culpados, ainda que se percebam como vítimas (em muitos casos o são de fato), mas isso os leva à imobilidade, à falta

5. Projeto de lei que tramita no Senado, propondo regulamentar os atos médicos e que tem apresentado muitas controvérsias, devido ao limitado conceito de doença e de tratamento, além de propor incluir limites à prática de outras categorias. 


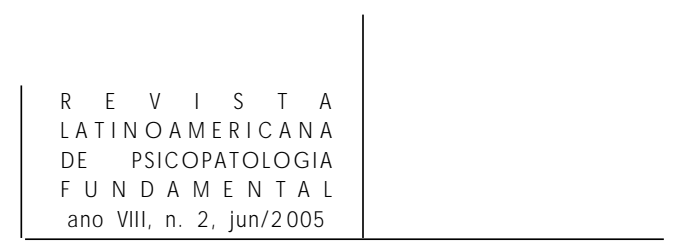

de solução, à confirmação da doença. Se nesse momento lhes apresentamos o "remédio", sabemos que este não é a cura, nem a restituição pura e simples ao estado anterior à crise ou ao surto. (p. 8)

Desde Hegel e Marx, desejo primeiro é desejo de reconhecimento. A abertura à palavra representa a aceitação do sujeito pelo outro. Este outro que opera uma ligação do real à fala, laços de Eros que historiciza a subjetividade e lança o sujeito na rede social. Mas há também o discurso total, a linguagem do Outro que mortifica (cf. Ciaccia, 2004) - uma alteridade mortífera para a subjetividade.

\section{Antônio, seu pathos e o encontro terapêutico ${ }^{6}$}

Antonio (nome dado por Erlich, 2003), brasileiro, natural do Rio de Janeiro, 72 anos, branco, casado, duas filhas adultas, segundo grau, aposentado (balconista de farmácia), religião católica.

Com uma história longa de internações, sendo as quatro últimas neste serviço, Antonio chega para ser reinternado devido à tentativa de suicídio motivo trazido pela família, pois sua mulher encontrou-o de pé sobre uma cadeira, com o intuito de se jogar pela janela $\left(10^{\circ}\right.$ andar $)$. Afirma não ter mais motivo para viver. Depois desta queixa, ele se alheou e se manteve cabisbaixo na entrevista. A história de sua doença atual (HDA) foi completada com os dados trazidos pela esposa. Como se ele não se encarregasse mais do seu caso, entregando-o aos outros. Entendemos que sua tentativa de suicídio foi um apelo para a família trazêlo de volta à internação. Foram poucos dias em casa, havia tido alta da penúltima internação e tinha demonstrado muita insegurança com essa saída. Como vem ocorrendo nos últimos anos, ele não tem conseguido sair das crises e retornar à vida normal. As relações familiares, aparentemente satisfatórias durante a maior parte de sua vida, tornaram-se muito difíceis, caracterizadas pelo afastamento e intolerância. Ele se tornou uma carga para a família, não conseguindo mais desfrutar da convivência nem manter o diálogo com as filhas e a esposa.

Até aos 45 anos Antonio levou uma vida saudável, trabalhando, tendo boa relação com a família, participando dos passeios e finais de semana em uma casa de veraneio. Nessa época começou a apresentar mudanças, tornou-se arredio, com humor retraído e afastou-se dos amigos e familiares, mantendo-se calado e

6. Além do contato pessoal, observações durante a internação, discussões em reunião de enfermaria e nas supervisões dos estagiários e residentes de psicologia, utilizo aqui os trabalhos apresentados pela residente de psicologia Hilana Erlich (2003 e publicado na Práxis, 2004) e de psiquiatria, Frederico B.H. Torres (2003). 
ARTIG O S

ano VIII, n. 2, jun/ 2005

clinofílico, além da perda do apetite e de insônia. Ele queria deixar o emprego, dizendo-se culpado por um roubo ocorrido no estabelecimento. Apesar de não haver nenhuma suspeita sobre ele, sentia-se objeto de desconfiança dos colegas. Falava para a esposa sobre sua angústia e idéias de suicídio, até que ingeriu comprimidos de estricnina e foi levado para a emergência hospitalar. Dessa emergência, ele foi encaminhado para a sua primeira internação em psiquiatria.

Foi nessa internação que ele recebeu pela primeira vez a Eletroconvulsoterapia (ECT), já que o antidepressivo não estava produzindo efeitos. Segundo informações dos familiares, depois de três aplicações, ele obteve melhora, recebeu alta da internação e continuou o atendimento psiquiátrico ambulatorial, retornando ao trabalho. Passou oito anos sem medicação e sem crises, até que voltou a apresentá-las cada vez mais freqüentemente, tendo várias internações em clínicas conveniadas até chegar à instituição atual.

Erlich (2003) descreve da seguinte forma sua primeira percepção do paciente: "O discurso psiquiátrico marcava a história e a forma com que Antônio se apresentava. Ele insistia em dizer que tinha depressão, nomeando o que sentia e desimplicando-se do que chamava 'minha doença'."

No espaço de internação - uma vila de casas, onde o interno partilha uma casa com mais três ou quatro, sendo cada quarto para dois. Além do pátio interno e das dependências, posto da enfermagem, refeitório, espaço para atividades - que são partilhados pelos internos (homens e mulheres). Nesta instituição, há uma proposta de se estabelecer uma convivência entre todos e de se estimular a interação entre os internos e a equipe, além da participação destes nas atividades oferecidas. Podem ainda receber visitas diárias de familiares, vizinhos e amigos. Há uma oferta e um convite para que saiam da posição passiva, do assujeitamento à doença e ao outro. Entretanto, Antonio não respondia a estas ofertas e solicitações, identificado que estava à sua doença.

Como já nos referimos acima, esta condição de doente não o apaziguava, sendo a sua angústia intensa e a sua solicitação aos médicos maior ainda. Da oferta diagnóstica, recebeu um nome para seu sofrimento; da oferta de cura, recebeu algo de forma inconsciente - a ECT - em que o submetimento é total e o sentido nenhum. Mas esse dispositivo, utilizado na primeira crise, deixou sua marca, fez desaparecer sua doença de forma milagrosa. Tanto ele quanto a família, depositaram nesse instrumento crenças e esperanças, buscando-o sempre que a depressão retornava. Se as marcas - culpabilidade - que levaram à eclosão de sua primeira crise deram uma trégua de oito anos, posteriormente as crises tornaramse mais freqüentes, ${ }^{7}$ e, nos últimos tempos, já não gozava de período normal.

7. A suspensão mais rápida das crises em distúrbios afetivos (PPMD), pela ECT e psicotrópicos, levou também a uma redução do período sem crise (Ey, 1986). 


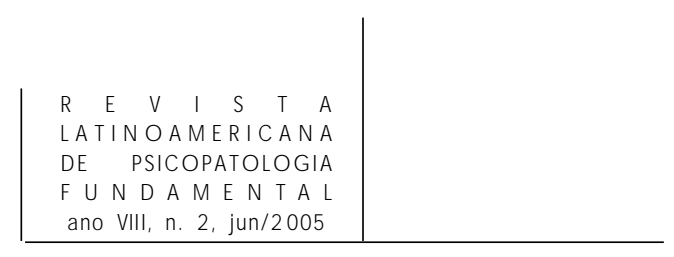

Nos vários anos de dependência do circuito psiquiátrico, experimentou todas as novas drogas que apareceram (Torres, 2003) e que prometiam fazer desaparecer a depressão através do re-equilíbrio neuroquímico. O seu esvaziamento, interno e externo, era grande. Não encontrava mais recursos subjetivos e vinculares que pudessem suportar a sua angústia. Buscava nesse grande outro, representado pela oferta do discurso médico, a poção derradeira que pudesse enviá-lo para o Nirvana. A solicitação da ECT nestes estados, além de uma função punidora - o castigo do supereu terrível - representa também a solicitação a este grande outro (a morte) de uma passagem para o outro mundo. Na penúltima internação nesta instituição, apelou-se para a ECT, mas sua resposta não foi boa, apresentando comportamento desorganizado e aspectos confusionais. Esta reação negativa serviu como argumento para nos contrapormos a uma nova indicação, e também para que pudéssemos repensá-la.

Reduzido ao seu estado de total submetimento à doença, Antônio repetia sua eterna cantilena: desde que saí daqui (última internação), não consigo mais dormir e nem comer, sinto uma confusão na cabeça que está me deixando louco. Tomo remédio todo dia e não adianta, fico pior, acho que nunca vou melhorar (Erlich, 2003). Não tinha mais desejo, não tinha mais motivo para viver.

Além dos cuidados que envolvem os agentes de todas as áreas, e apesar da resistência, Antônio começou a aceitar a oferta da psicóloga. Não desejar conversar, não ter nada para falar, foi cedendo e ele começou a responder à aproximação tranqüila e confiante desta. Ela acreditou neste investimento e em sua aposta de que, pela palavra, ele poderia romper a repetição e de que na transferência poderia criar um espaço de circulação e de desdobramento.

Estes pacientes buscam no espaço da internação um invólucro de proteção, mas na medida em que se colocam dentro deste invólucro, não podem circular, tornam-se fixados em suas iterações. Por isto, valorizamos as tentativas de criar alternativas, dialetizando o espaço mediante o deslocamento interno/externo. Estes recursos foram utilizados por Hilana que o convidou a passear no pátio externo à vila propondo conversarem e tomar água de côco, o que ele passou a aceitar. Nesse deslocamento espacial ele foi se abrindo à fala. A partir daí, na enfermaria não contava somente com o médico e com os enfermeiros para solicitar o alívio de sua angústia. Um espaço de expectativa se produziu, pois alguém viria encontrá-lo e ele poderia falar de outras coisas, ou seja, as coisas que não tinham mais valor começaram a ganhar vida. Ele tem duas filhas, com quem não estava conseguindo relacionar-se. Uma, inclusive médica, mas que nunca a vimos visitálo. Não as censuramos, pois sabemos o quanto é penosa a convivência com o negativo do vazio depressivo. ${ }^{8}$ Freud (1915) afirma que devemos levar a sério o

8. Estou utilizando o termo depressivo, pois não encontrei neste paciente os elementos da melancolia. 


\section{ARTIG OS}

ano VIII, n. 2, jun $/ 2005$

melancólico quando este insiste em dizer que prejudica a família, que lhe causa grande mal, pois as forças destrutivas que nele operam atingem os que estão à sua volta. Nestes casos, o que sugerimos é que a família seja contatada sem cobranças e exigências, e que seja dito que ali também encontrarão uma oferta de atenção e de suporte.

Suponho que esta proximidade com uma outra que não a sua própria filha - a psicóloga - mas que poderia ser sua filha, favoreceu elementos transferenciais positivos. Em outras situações, também pudemos observar uma certa facilitação transferencial no relacionamento entre terapeutas jovens e pacientes com mais idade. O jovem afeta com sua marca de Eros: fruição da vida, afirmação e maior espontaneidade. Portanto, este caso contrapõe ao pacote operacional e prova que a psicanálise tem o que fazer até mesmo em impasses na clínica psiquiátrica.

A intervenção do DSM-IV no campo psiquiátrico, com sua referência operacional, trouxe em seu bojo um pacote pronto e acabado - TOC, TP e TD (transtorno obsessivo compulsivo, transtorno de pânico e transtorno depressivo) - transtornos estes cuja origem primária seria neuroquímica, cuja prescrição vem determinada a priori: mesmas drogas e complemento psicoterápico cognitivocomportamental, incluindo a contra-indicação da psicanálise (cf. Pereira, 1997). Esta crença tem uma força entre os médicos, pois restaura o sonho psiquiátrico de ser uma verdadeira medicina. ${ }^{9}$ Mas sem a psicopatologia e o estudo da psique, a psiquiatria será reduzida a uma neuroquímica pobre e a prática do psiquiatra perderá a sua singularidade.

Em nosso caso, confrontamos esta crença medicalista e a oferta psicanalítica foi mantida e sustentada. Seu movimento de saltar pela janela, por exemplo, foi entendido como um grito que deveria ser escutado e não simplesmente medicado como sintoma da depressão. Como afirmou Erlich (2003: “A chance de the oferecer uma escuta psicanalítica era apostar num outro destino que rompesse com o ciclo de internações, abrindo espaço à palavra. Internar não deveria ser sinônimo de enterrar, ao contrário, tratava-se de desenterrar, de resgatar este sujeito que estava desaparecido, esquecido" (p. 4).

Quando o sujeito não sofre uma inibição maior, do tipo hibernação (hiposensorialidade, no sentido de Berlinck, 2000) - que parece servir de proteção para o eu desterrado - ele sofre muito lutando contra a tenacidade das idéias negativas - pensamentos ruins, idéias de acabar com a vida - que insistem

9. Como afirma Rinaldi (2002, p. 63), seguindo Roudinesco, "o discurso medicalizante da psiquiatria biológica, fundado na verdade científica e eficiência, exerce um enorme poder de sedução sobre os médicos em formação na instituição, uma vez que responde aos anseios de sucesso de uma sociedade de consumidores que procura eliminar, a qualquer preço e no menor tempo possível, o sofrimento psíquico como marca do sujeito”.

\section{5}




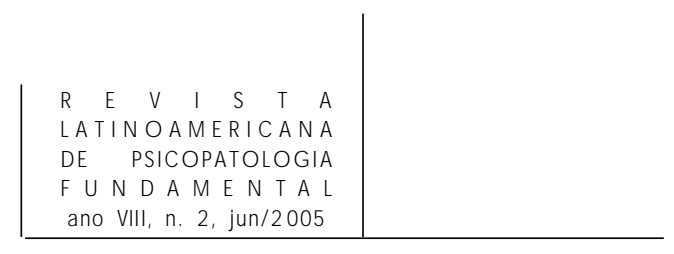

intensamente, como se o eu estivesse na mão dos algozes. Neste caso, o espaço criado na relação terapêutica permitiu que o eu pudesse exercitar-se com alguma atividade e domínio, encontrando um pouco de liberdade ao jugo do supereu terrorífico.

Nesta clínica múltipla, em que somos instigados o tempo todo - por questões da equipe, por novas internações de pessoas em estados graves e mobilizantes, que envolvem os profissionais etc. - a tentativa de construir os planos terapêuticos é fundamental e, como já dissemos, é uma construção muitas vezes bricolada, mas mesmo este arranjo fragmentado é de grande importância para a direção do tratamento. Como lembra Berlinck, ${ }^{10}$ é necessário um afastamento para a elaboração. Entendemos que estes momentos de discussão franca, que por vezes acontecem na instituição, permitem que nos descolemos um pouco da experiência e das vivências contratransferenciais, surgindo a possibilidade de circulação. Se isto acontece, o paciente deixa de ser meu e passamos a trabalhar a tarefa terapêutica - talvez o que Lacan chamou de transferência de trabalho.

Neste caso, foi possível garantir um plano terapêutico a partir da superação do pessimismo e do impasse na equipe devido à indicação da ECT. Como esta indicação veio como determinação do discurso médico - não há nenhuma melhora, como se trata de depressão, a ECT é uma intervenção eletiva - provocou reação nos demais. Primeiro surgiu a barreira das corporações - porque vocês são contra a ECT. Na verdade, os assistentes sociais e enfermeiros, que já conheciam bem o paciente, também sabiam que este recurso não iria beneficiá-lo em nada. A discussão foi possível a partir da exigência de um princípio: não aceitamos discutir a nível de pró e contra, só discutiremos a partir da clínica. Esta avaliação clínica exigia que todos pudessem ter a sua palavra garantida, podendo falar de seus anseios, observações clínicas, do dia-a-dia, da história na instituição, do trabalho com a família e da reflexão sobre os recursos utilizados até então.

O residente de medicina vinha se esforçando ao máximo e havia registrado dados que facilitavam a diferenciação diagnóstica, ou seja, não era possível falar de um negativismo extremo, não havia delírios de ruína, nem recusa alimentar. ${ }^{11}$

10. Comunicação pessoal, Seminários-PUC/SP, 2003.

11. Em outro momento discutiremos a diferenciação diagnóstica. Os termos depressão/melancolia são objetos de controvérsias, desde que Kraepelin classificou a PPMD. O termo melancolia que no século XIX chegou a ser sinônimo de loucura - foi substituído por depressão, sendo necessário acrescentar-lhe um adjetivo (Depressão Maior ou Menor), para diferenciar endógeno e exógeno. Depressão surgiu de lipemania de Esquirol (Pessotti,1999) onde foi dado o acento no abatimento, uma figura da geologia (Ferreira, 2002a). Vários estudiosos e psicanalistas atualmente procuram discutir estas diferenciações e afirmar a categoria da melancolia (Berlinck, 2002; Peres, 1996; Quinet/Alberti (In: Almeida/Moura, 1997) etc.). 
As idéias de se matar foram entendidas como pedido de socorro. Além disso, a sua reação anterior à ECT foi bastante negativa. Desta forma, foi possível sustentar a continuação de seu tratamento. Como afirma Erlich (2003):

A aposta na palavra era radical, não só na do paciente, mas também na nossa palavra, enquanto palavra de diferença. A nosso ver, a aplicação da ECT neste sujeito mortificado, reforçaria a repetição e mataria a sua possibilidade de falar. Seria calar a voz, que já começava a se pronunciar. Bancar esta posição, trouxe alguns efeitos para o trabalho em equipe. Houve uma maior circulação da palavra, ao invés desta ficar concentrada num único profissional. (p. 4)

Quando se compartilha a clínica intensiva, ela se torna bem mais leve para todos. Sobre o médico, muitas vezes recai a grande carga, seja da família, querendo resultados e explicações diagnósticas e terapêuticas, seja devido ao lugar que este ocupa no discurso do mestre. Neste caso, a dupla terapêutica de referência pode se compor e partilhar o trabalho terapêutico. Um elemento sugerido pelo médico - uma medicação nova - reforçou a esperança do paciente (resposta transferencial).

A alta da internação não foi fácil, pois ele apresentava muitos temores e insegurança, além de dificuldades de encarar a família na qual se sentia desvalorizado e como um peso. Mas o trabalho com a família pôde garantir uma maior confiança para todos, pois ele não estava sendo abandonado e estaria assegurado o seu tratamento no ambulatório. Tudo isto, no entanto, não impediu que trouxesse com freqüência as suas solicitações de internação, de aumento da medicação e da ECT.

O trabalho de elaboração desta passagem da internação para o tratamento e para a vida externa é, a nosso ver, fundamental na continuidade do mesmo. Se não houver uma posição firme e de confiança dos terapeutas, a reinternação surge como resposta à demanda não transformada em comprometimento subjetivo. Para que o paciente possa se comprometer com seu tratamento, é necessário que encontre no outro um suporte. A saída da internação é um momento sensível e exige atenção do projeto da reforma psiquiátrica, pois dele depende boa parte de seu sucesso. A internação deve ser vista como uma interface da assistência, ou seja, o interno e o externo devem representar as interfaces do projeto terapêutico de uma instituição psiquiátrica.

Foi bastante gratificante ver este paciente vir ao encontro de sua terapeuta no ambulatório. Havia a expectativa e a dúvida: ele virá mesmo para a psicoterapia no ambulatório? E lá vinha ele, com a apresentação caprichada esperando por sua psicóloga. Mais tarde dirá que está retomando várias atividades junto com sua esposa e filhas, está podendo desfrutar dos passeios, da casa de veraneio e está conseguindo fazer amor. Foi possível o surgimento do trabalho de Eros, ocor- 


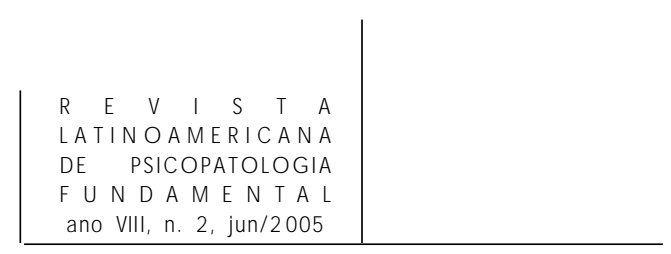

rendo aí uma "passagem da depressão para a depressividade" (Berlinck, 2000, p. 83), o que vem permitindo a continuidade de seu atendimento externo. Como este atendimento externo está sendo possível há dois anos, entendemos que a opção foi a mais correta, já que o tratamento tradicional só estava agravando a sua alienação. Sem entrar na controvérsia da ECT, seu emprego neste caso acentuava o seu submetimento ao instrumento médico. Lembramos ainda, que Antônio não apresentava mais períodos intercrises, vinha se cronificando na instituição da internação.

Acredito que foi gratificante para toda a equipe o fato de ter sido superado um impasse inicial e de ter sustentado um trabalho interprofissional. Neste sentido, este trabalho vem refletir um pouco de minha perspectiva nestas mais de duas décadas de instituição psiquiátrica, onde tenho tentado sustentar este esforço de manter a interlocução e de intervir sempre contra o corporativismo. A criação do outro (os enfermeiros, os psicólogos os médicos etc.) é investido do narcisismo das pequenas diferenças, que ao radicalizar-se destrói as condições éticas e transforma a convivência em algo insuportável.

Agradeço a psicóloga Margarete Simões Ferreira, pela leitura cuidadosa e pelas contribuições.

\section{Referências}

AlberTI, Sônia. Psicanálise e medicina. Práxis e formação, IP/NAPE/UERJ, n. 6. , 2003 (no prelo).

Almeida/Moura (orgs.). A dor do existir. Rio de janeiro: ContraCapa, 1997.

Berlinck, Manoel Tosta. Psicopatologia fundamental. São Paulo: Escuta, 2000.

Comunicação em aula. Seminários. LPF/PUCSP, 2003/2004.

CAON, José Luiz, Retrato. Auto-retrato e construção metapsicológica de Serguéi Pankejeff, o Homem dos lobos. Pulsional Revista de Psicanálise, São Paulo, ano XII, n. 140/141, p. 22-44, dez.2000/jab.2001.

CiAcCIA, Antonio Di. La pratiques à plusieurs (Il bambino autistico e la struttura). Divulgação eletrônica, 2003). Obs. Este texto será publicado em AltoÉ/Mello (org.). Psicanálise e instituição. Rio de Janeiro: Mestrado em psicanálise/IP/Riosambiciosos, 2004.

D’ARgord, Marta. Uma construção de caso na aprendizagem. Pulsional Revista de Psicanálise, São Paulo, ano XII, n. 140/141, p. 12-21, dez.2000/jan.2001.

ERLICH, Hilana. Apostando num sujeito esquecido. Práxis e formação, IP/UERJ, n. 6, p. 133-9, 2004. 


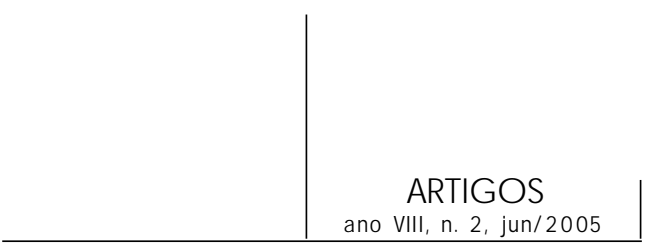

Ey, Henri. Manual de Psiquiatria. Rio de Janeiro: Toray-Masson, 1986.

FERreira, Ademir Pacelli. O migrante na rede do outro: ensaios sobre alteridade e subjetividade. Rio de Janeiro: Te Corá, 1999.

Melancolia: da diversidade fenomênica à diferenciação estrutural. Psicologia Clínica, PUC-RJ, v. 14, n. 2, 2002a.

O ensino da psicopatologia: do modelo asilar à clínica da interação. Revista Latinoamericana de Psicopatologia Fundamental, São Paulo, v. V, n. 4, p. 12-29, dez./ 2002b.

Figueiredo, Ana Cristina. Da psicanálise à psiquiatria: a propósito de um método. $R e$ vista Latinoamericana de Psicopatologia Fundamental, São Paulo, v. V, n. 4, dez./2002.

(2003). A construção do caso clínico: uma contribuição da psicanálise à psicopatologia e à saúde mental. VII Encontro Científico da AUPPF, Revista Latinoamericana de Psicopatologia Fundamental, São Paulo, v. VII, n. 1, p. 75-86, 2004.

Foucault, Michel. O nascimento da clínica. Rio de Janeiro: Fu, 1977.

FREUd, Sigmund (1915). Luto e melancolia. In: ESB. Rio de Janeiro: Imago, 1974. v. XIV.

Freud, Sigmund/Jung, Karl G. (1907). Correspondência completa. Rio de Janeiro: Imago, 1976.

Hoppe, Marha Wankler. Do modelo narrativo à escritura do fato clínico: o drama do paciente e o caso do analista. Pulsional Revista de Psicanálise, São Paulo, ano XII, n. 140/141, p. 56-62, dez.2000/jan.2001.

Nasio, J.-D. Os grandes casos de psicose. Rio de Janeiro: Jorge Zahar, 2001.

Oliveira, Daniela Coelho de. A neutralização da diferença: a loucura na cena analítica contemporânea. 2004. Tese (doutorado em Psicologia), IP/UFRJ.

Pereira, Mario E. Costa. Pânico: contribuição à psicopatologia dos ataques de pânico. São Paulo: Lemos, 1997.

Pânico e desamparo: um estudo psicanalítico. São Paulo: Escuta, 1999.

Peres, Urania Tourinho (org.). Melancolia. São Paulo: Escuta, 1996.

Pessotti, Isaias. Os nomes da loucura. Rio de Janeiro: Ed. 34, 1999.

RinAlDi, Doris. O desejo do psicanalista no campo da saúde mental: problemas e impasses da inserção da psicanálise em um hospital universitário. In: RINALDI, Doris e CouTinHo Jorge (orgs.). Saber, verdade e gozo. Rio de Janeiro: Rios Ambiciosos, 2002.

Stevens, Alexandre. Psychanalyse et santé Mentale. Revue de l'Ecole de la cause freudienne-Belgique, Quarto 59, p. 23-5, 1996.

Torres, Frederico B. H. Rodrigues. Sessão clínica. UDAP/HUPE, 11/2003.

VigAnó, Carlo. Depressão e psicofarmacologia. In: Saúde mental: psiquiatria e psicanálise. Belo Horizonte: ISM/AMP, 1997. 


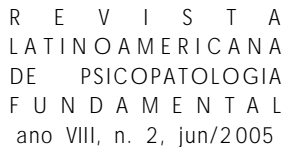

\section{Resumos}

La construcción del caso es aquí abordada en su pluralidad práctica en la internación psiquiátrica. De inicio se presenta una revisión sucinta de la concepción y de la metodología del caso clínico. Seguidamente se pasa a la construcción y análisis del caso, donde se afirma su importancia en la dirección del plan terapéutico. Finalmente, se llama la atención para la relevancia de la elaboración del momento de la salida de la internación para el suceso de la continuidad del tratamiento externo.

Palabras claves: Caso clínico, pluralidad, construcción, internación, reforma psiquiátrica

La construction du cas est ici centrée sur la pluralité pratique de l'internement psychiatrique. Il débute par une révision succincte des concepts et de la méthodologie du cas clinique, puis se poursuit par la construction et l'analyse du cas qui révèle son importance dans la direction et l'accompagnement du plan thérapeutique. Finalement, l'accent est mis sur la nécessité d'élaborer le moment de la sortie de l'internement, comme condition au succès de la continuité du traitement externe.

Mots clés: Cas clinique, pluralité, construction, internement, réforme psychiatrique

The construction of the case is approached here in its practical plurality in the psychiatric internment. At first, a synthetical review of clinical case methodology and concepts are presented, following the case construction and analysis to support its importance to the therapeutic plans direction. Finally, attention is called to the relevance of the elaboration of the internation exit moment for the sucess of external treatment continuity.

Key words: Clinical case, plurallity, construction, internation, psychiatryc reform 